\title{
Introducing Plan Oblique Relief
}

Plan oblique relief is a new digital technique for rendering threedimensional terrain on otherwise planimetric (conventional flat) maps. Landforms shown realistically in side view have an illustrative quality that appeals to readers. Inspired by the work of manual mapmakers of the past, the paper begins with a historical review that includes maps by Xaver Imfeld of Switzerland, Erwin Raisz of the United States, and Heinrich Berann of Austria. In the next, digital techniques section, the projections and rendering parameters needed to create plan oblique relief receive attention, as does Natural Scene Designer 5.0, the first commercial software to offer this functionality. The section on design takes a candid look at the advantages and disadvantages of plan oblique relief. The paper ends on a practical note by discussing two maps made by the authors that feature plan oblique relief, one a panorama and the other a physical map.

Keywords: Plan oblique relief, 3D digital terrain rendering, landform maps.

$\mathrm{T}$ errain presented in side view and with three-dimensionality on planimetric maps has a long history in mapmaking. As a presentation style, it draws the attention of readers, is easy to understand, and spurs the imagination. This paper offers a digital solution for creating plan oblique relief-the name we use for the "standing up" style of terrain presentation exemplified by the landform maps of Erwin Raisz and other terrain mapping specialists of the manual era. The term "plan oblique" appeared in an article by Carlbom and Paciorek (1978) that described a technique for drafting three-dimensional buildings, which we have adapted for relief mapping. Plan oblique relief, however, is hardly new to mapmaking and goes by other names, most of which are arcane, polysyllabic, and difficult to remember ${ }^{1}$. For the sake of consistency, in this article we use the term plan oblique relief exclusively.

Although shaded relief maps and 3D perspective views are common today, plan oblique relief remains uncommon because, until now, no commercial software application has included it as a rendering option. The software and techniques introduced in the pages that follow provide cartographers with a means to produce plan oblique relief with relative ease. The choice now facing cartographers is not so much how to make plan oblique relief but when to use it and how best to present itthat this paper explores.

Plan oblique relief contains the characteristics of both conventional shaded relief and 3D perspective views, such as panoramas. As the "plan"

${ }^{1}$ Other names for plan oblique relief include: 3D planimetric relief, high oblique relief, oblique orthographic shaded relief, landform map, morphographic map, physiographic map, and proportional relief landform map.

Initial submission, December 13, 2006; revised submission, March 14, 2007; final acceptance, March 25, 2007

\section{Bernhard Jenny}

Institute of Cartography

ETH Zurich, Switzerland

jenny@karto.baug.ethz.ch

Tom Patterson

U.S. National Park Service

Harpers Ferry, WV, USA

tom_patterson@nps.gov

\section{INTRODUCTION}

"Plan oblique relief contains the characteristics of both conventional shaded relief and $3 D$ perspective views, such as panoramas." 

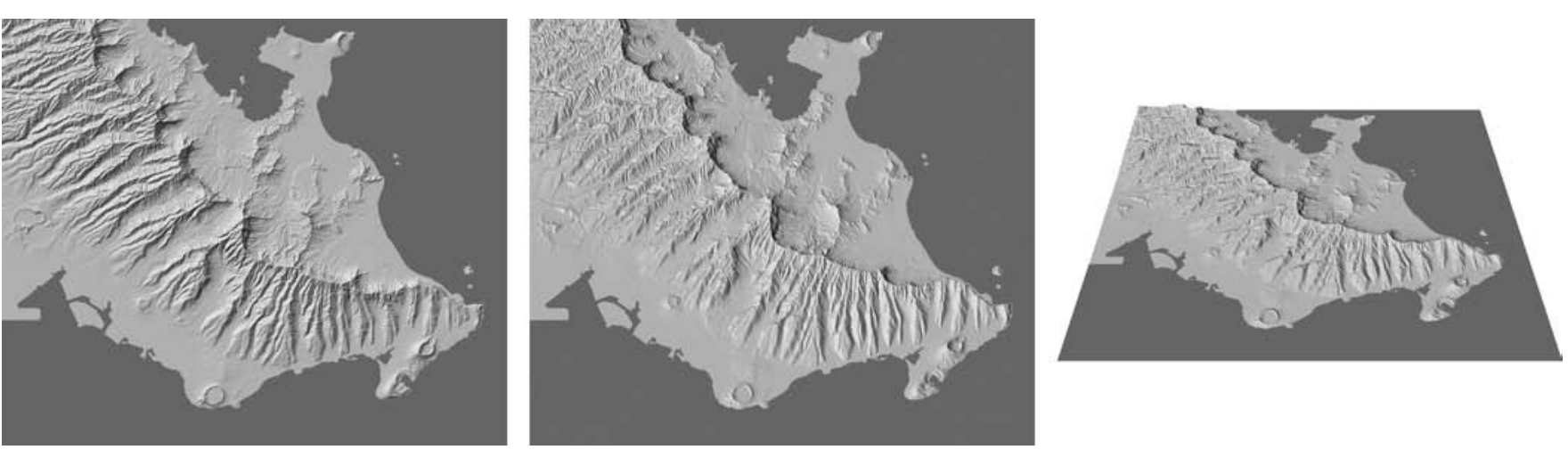

Figure 1. Southeastern Oahu, Hawaii, rendered as conventional shaded relief (left), plan oblique relief (center), and as a 3D perspective view (right). (see page 88 for color version)

"Compared to $3 D$ perspective views that look most natural of all, plan oblique relief better preserves geographic shapes without any front-to-back foreshortening and convergence toward a distant vanishing point." in its name suggests, plan oblique relief uses a planimetric base for its initial construction, as do most shaded relief maps. The "oblique" in its name refers to the shallow angle used for rendering the terrain-but in a manner that eliminates the occurrence of perspective. On conventional shaded relief maps, terrain rendering occurs from a theoretical position directly

overhead and infinitely distant. Plan oblique relief uses a lower position, somewhere between directly overhead (90 degrees) and the horizon (0 degrees). This results in 3D terrain that projects upwards, perpendicular to the bottom of the map and parallel to the reader's view (Figure 1).

The effect of plan oblique relief is not unlike axonometric city maps, such as the famous Bollmann map of Manhattan (Hodgkiss, 1973), but with three-dimensionality applied not to buildings but to terrain. Because plan oblique relief portrays the landscape much like how people see it in their everyday lives-from a horizontal perspective - the authors contend that it is easier for novice readers (and even experts) to understand it at a glance than to understand conventional shaded relief. High solitary mountains, such as Mt. Fuji and Mt. Kilimanjaro, which appear as indistinct dots on a small-scale shaded relief map viewed from above, reveal their recognizable forms and appear as the major mountains that they are when rendered in plan oblique relief. Compared to 3D perspective views that look most natural of all, plan oblique relief better preserves geographic shapes without any front-to-back foreshortening and convergence toward a distant vanishing point. 3D perspective views mimic the view from an airplane window; plan oblique relief is suited to mapmaking.

The presentation of plan oblique relief on maps can appear in several styles ranging from high contrast line drawings to continuous tone renderings in grayscale or color. Regardless of its appearance, using plan oblique relief does come with a price, however. Points on the 3D terrain surface exhibit planimetric displacement with increasing altitude. For example, the base of Mt. Fuji at sea level would be planimetrically correct, but its summit would shift noticeably toward the top of the page, depending on the map scale and amount of vertical exaggeration. After the initial rendering of a plan oblique relief map, planimetric displacement makes it difficult to overlay data obtained from other sources, even if the projection and scale are the same. A later section will discuss this and other problems associated with plan oblique relief in detail. 


\section{PLAN OBLIQUE RELIEF OF THE MANUAL ERA}

Although new to digital cartographers, plan oblique relief has not always been as rare and exotic as it is today. One of the earliest known maps, an approximately 5,000-year-old clay tablet from Mesopotamia, depicts mountains in profile with simple hump-shaped mounds. This example, a primitive form of plan oblique relief, was to reign in various forms for millennia as the dominant method of relief portrayal on maps. Leonardo da Vinci's map of Tuscany drawn in 1502-1503 portrays hills in an oblique fashion and with the refinement one would expect from that artist (Imhof, 1982). Even today, given a blank outline map and the pop assignment to depict the Andes, most people would fill the western edge of South America with a row of symbols that look like inverted V's. Few readers would mistake this symbology for anything other than mountains.

For the past two centuries as cartography became a formal profession and sought to become more scientific, so too has plan oblique relief. However, in this same period, plan oblique relief fell out of vogue in favor of other methods of relief portrayal, such as hachures, contours, hypsometric tints, and shaded relief. Although plan oblique relief declined in relative popularity as the profession modernized, relief maps made during this period are among the most accomplished examples of the genre-and for that matter the entire discipline. The following is a review of notable cartographers who have used plan oblique relief.

\section{Xaver Imfeld (1853-1909)}

Our review of plan oblique relief begins with Xaver Imfeld's "Reliefkarte der Centralschweiz" published in 1887, which shows the Lake Lucerne region of Switzerland with the detail and artistic refinement that has become a hallmark of later Swiss topographic maps (Figure 2). Besides being a cartographer, Imfeld was a talented topographer, relief model maker, and railway engineer (Cavelti Hammer et al., 2006), factors that may have influenced his ideas about mapmaking.

Unusual features on the "Reliefkarte der Centralschweiz" include southwest orientation, illumination originating from the lower right, and a

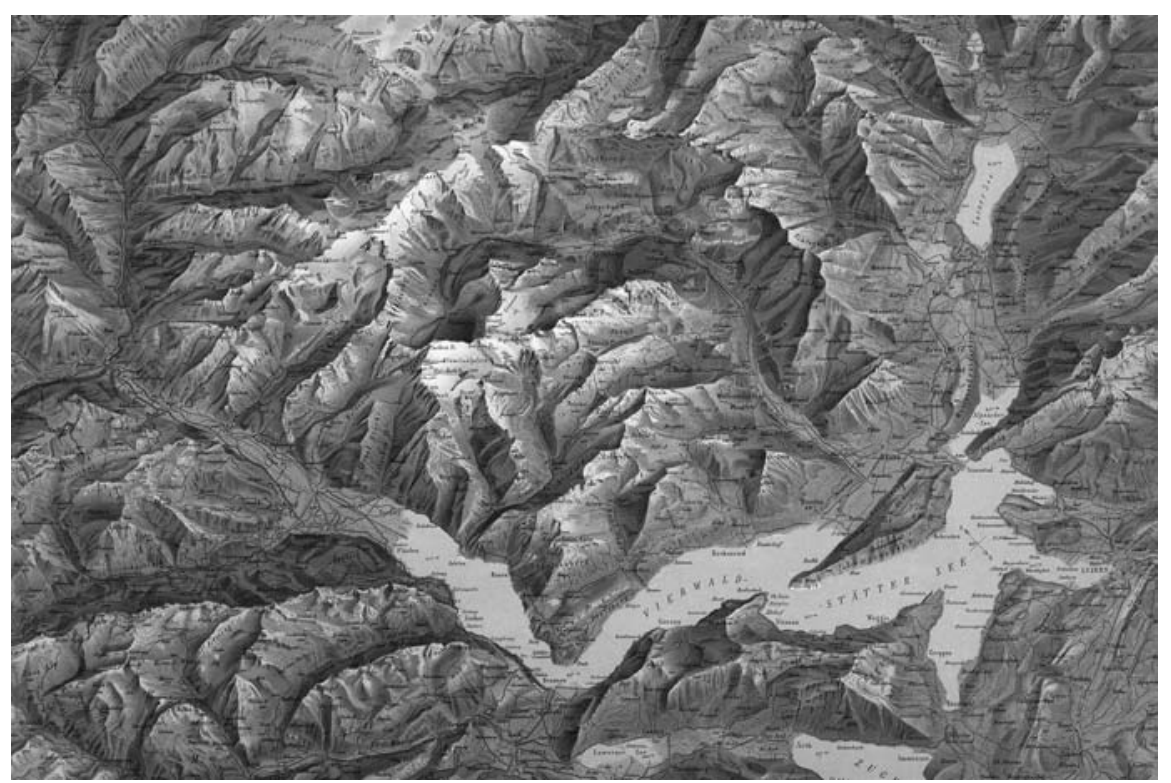

Figure 2. Xaver Imfeld's "Reliefkarte der Centralschweiz." (see page 88 for color version)
"Besides being a cartographer, Imfeld was a talented topographer, relief model maker, and railway engineer (Cavelti Hammer et al., 2006), factors that may have influenced his ideas about mapmaking." 
"With only a few expertly placed strokes of the pen Raisz captured the look of complex physical features. His maps are in essence caricatures, but with the landscape as the subject matter and accuracy a key consideration." ground plane depicted at two different scales. The horizontal (left to right) axis of the map is at 1:100,000-scale and the vertical (top to bottom) axis is at 1:141,000-scale. According to Imfeld's explanation on the 1898 printing of the map, the southwest orientation shows the terrain as most tourists (the potential buyers of this map) would see it as they approached the Alps from the north. The "Reliefkarte der Centralschweiz" was the only map made by Imfeld with three-dimensional terrain depiction; contemporary cartographers did not imitate his technique. Although the varying ground scales technically disqualify the map as planimetric, the continuous-tone relief and inclusion of glacier textures are similar to that of plan oblique relief created digitally.

\section{Erwin Raisz (1893-1968)}

The landform maps drawn by Harvard lecturer Erwin Raisz a half-century ago are the cartographic outgrowth of the physiographic block diagrams pioneered in the late 1800s by William Morris Davis and later refined by Armin Lobeck (Raisz, 1956). Using only a pen, aerial photography and topographic map references, and his considerable knowledge of physical geography, Raisz depicted landforms with 50 classes of pictorial symbology selected from a pre-made library (Raisz, 1931). Raisz modified these pictorial symbols as needed to best represent intermediate landform types. With only a few expertly placed strokes of the pen Raisz captured the look of complex physical features. His maps are in essence caricatures, but with the landscape as the subject matter and accuracy a key consideration (Figure 3, left). The presentation style developed by Raisz using black strokes on a white background differs from plan oblique relief rendered in color or shades of gray by manual or new digital methods. Raisz's technique, however, relates closely to plan oblique relief, since it depicts mountains with a similar side view on an approximately planimetric ground plane.

Because Raisz constructed his maps on flat planimetric bases, they depict the relative elevation of landforms poorly. This is most problematic where the terrain is flat or slopes gradually. For instance, on his 1:4,525,000-scale "Landform Map of the United States," the Central Valley of California just above sea level and the San Luis Valley of Colorado at an elevation of 2,200 meters seem to be at the same elevation on the printed sheet, presumably at sea level. Further complicating matters, Raisz gave disproportionate emphasis to low, flat terrain and deemphasized high mountains, which exhibited no more than 2 millimeters of vertical offset in the Sierra Nevada and Colorado Rockies (Raisz, 1956). To make up for the lack of pictorial cues about elevation differences, Raisz sprinkled his maps with many spot elevations.

A proportional relief landform map of Utah produced by Merrill K. Ridd (1963) attempted to improve on Raisz's technique. Seeking to show the height of landforms properly proportioned, Ridd subdivided his map into a patchwork of "local bases," typically defined by valley bottoms or drainages, to which he assigned average lowland elevations. The average lowland elevations differed for each local base. He then plotted the height of mountains and plateaus within these local bases, taking into account the local relief. Despite this effort, Ridd's technique also failed to represent gradual slopes and the elevation of flat lowland areas correctly throughout the map. Because his base map (and the local bases that he drew on it) was planimetric, all flat areas occupied the same visual plane regardless of their differing elevations.

There are three probable reasons why Raisz and Ridd drew landform maps on a flat plane: the tedium of calculating accurate elevations over 
large sloping regions, such at the Great Plains, with little in the way of terrain variation to show for the effort; the difficulty of depicting these subtle changes with an inked line; and the desire to keep drainages and other map linework strictly planimetric. Given these factors, the purpose of their maps, and the tools and data they had to work with then, they made the right decision.

\section{Heinrich Berann (1915-1999)}

Austrian artist Heinrich Berann is best known for his painted panoramas of the Alps at large scales. Less well known is his prolific work with plan oblique relief. Most of this effort takes the form of small-scale views of continents and countries that to the average reader look little different from his large-scale panoramas. For example, arcing horizons, ethereal cloudscapes, background haze, and other typical Berann flourishes disguise the true nature of these maps. They are in fact planimetric base maps that Berann cleverly distorted near the top of the printed sheet to give them a false impression of front-to-back depth, much like a true panorama. Terrain representation in the fore- and middle-ground of these scenes, however, is plan oblique relief.

In the 1960s and 70s, Berann lent his considerable artistic skill to an important scientific project. Through contacts at the National Geographic Society, he teamed up with Marie Tharp and Bruce Heezen of Columbia University to create a series of maps showing the ocean floors as though drained of water (Figure 3, right). Tharp and Heezen had spent decades collecting and analyzing depth soundings collected by ships from around the world (Lawrence, 1999). Berann's job was to interpret these voluminous raw data so that the public could easily visualize them. He chose to depict the undersea topography with plan oblique relief. The work culminated in 1977 with a world map that revealed a previously unknown environment. Readers for the first time could see that the mid-Atlantic ridge was but one section of a 64,000-kilometer-long chain of undersea mountains - the largest topographic feature on Earth. The U.S. Navy and National Geographic Society published the map. Writing in Mercator's World (1999), David Lawrence stated "The masterwork by Tharp, Heezen,

\author{
"The work culminated in 1977 \\ with a world map that revealed \\ a previously unknown \\ environment."
}
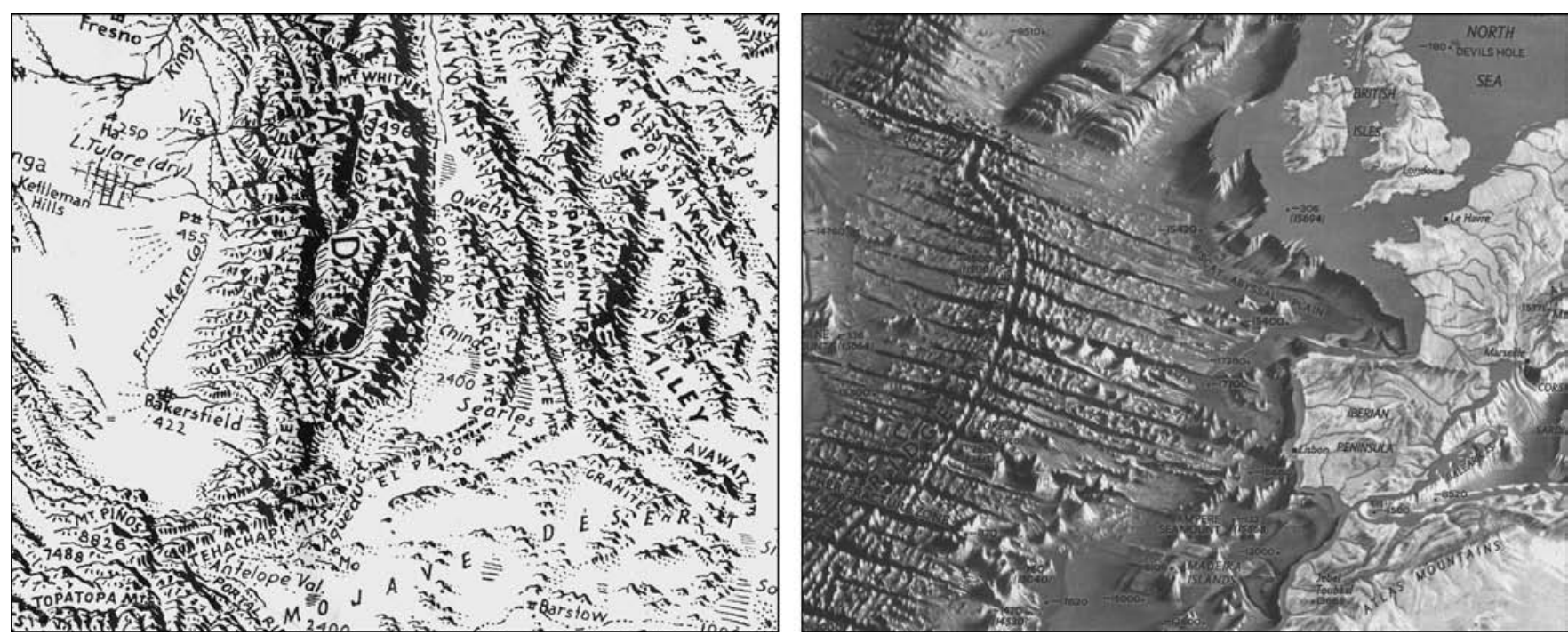

Figure 3. A sample from Erwin Raisz's 1957 "Landforms of the United States" (left) and Heinrich Berann's 1968 “Atlantic Ocean Floor," published by National Geographic Society (right). Note that Raisz uses lower left illumination and Berann lower right illumination. (see page 89 for color version) 
"Inclined contours are hybrids between typical contour lines and vertical profiles." and Berann is possibly the closest thing Earth science has to iconography." It helped win over remaining skeptics for the then still developing theories of plate tectonics and ocean floor spreading.

\section{Inclined contours vs. plan oblique relief}

No historical review of plan oblique relief would be complete without reference to the well-known inclined contour technique developed by Tanaka (1932) and later adapted by Robinson and Thrower (1957), which they renamed "traces of parallel inclined planes." Inclined contours are hybrids between typical contour lines and vertical profiles. Creating them involves tilting a series of inclined planes generally to the south and drawing traces where the planes intersect the terrain surface. To novice readers this technique could look like plan oblique relief, but it differs significantly. The resulting terrain is not truly three-dimensional and appears on a base that is entirely planimetric, both in the lowlands and on mountaintops. Despite the obvious advantages that planimetric terrain depiction offers, in the 75 years since inclined contours were first introduced, few mapmakers have used them for other than experimental projects. Possible factors preventing widespread adoption include: terrain portrayed with distracting parallel lines that interferes with other map information; the usual difficulties with manual production; and the conceptual leap of faith that readers must make to accept simulated 3D terrain on a flat planimetric surface. Because inclined contours lack the planimetric displacement found in plan oblique relief, the technique depicts terrain in a much less believable fashion. GIS technology now can generate inclined contours like those produced manually (Kennelly, 2002). Regardless of this development, the technique is likely to remain more intriguing than useful for mapmaking.

\section{Current use of plan oblique relief}

Today, plan oblique relief is perhaps most common on the decorative reference maps found in books on travel, history, and popular fiction-for example, the fanciful map of Middle Earth found in Tolkien's Lord of the Rings (1994). One occasionally encounters eye-catching tourist maps that feature hand-rendered plan oblique relief (Figure 4). Practitioners of this mapping niche, which undoubtedly includes more graphic artists than cartographers, draw or paint plan oblique relief by hand. In the sections that follow we discuss how cartographers can now do this with digital tools.

\section{DIGITAL PLAN OBLIQUE RELIEF}

To investigate the properties of plan oblique maps, we developed prototype software for rendering digital terrain. This software renders plan oblique relief with continuous-tone gray values similar to those found in conventional shaded relief. It uses standard digital elevation models and can drape raster imagery onto the terrain. Compared to the many parameters (position, azimuth, zenith, and field of view of the camera) that determine the look of typical 3D perspective views, plan oblique relief is very easy to configure.

\section{Projection method}

Rendering plan oblique relief (and other varieties of relief) involves projection methods that are unrelated to common 2D map projections, such as 


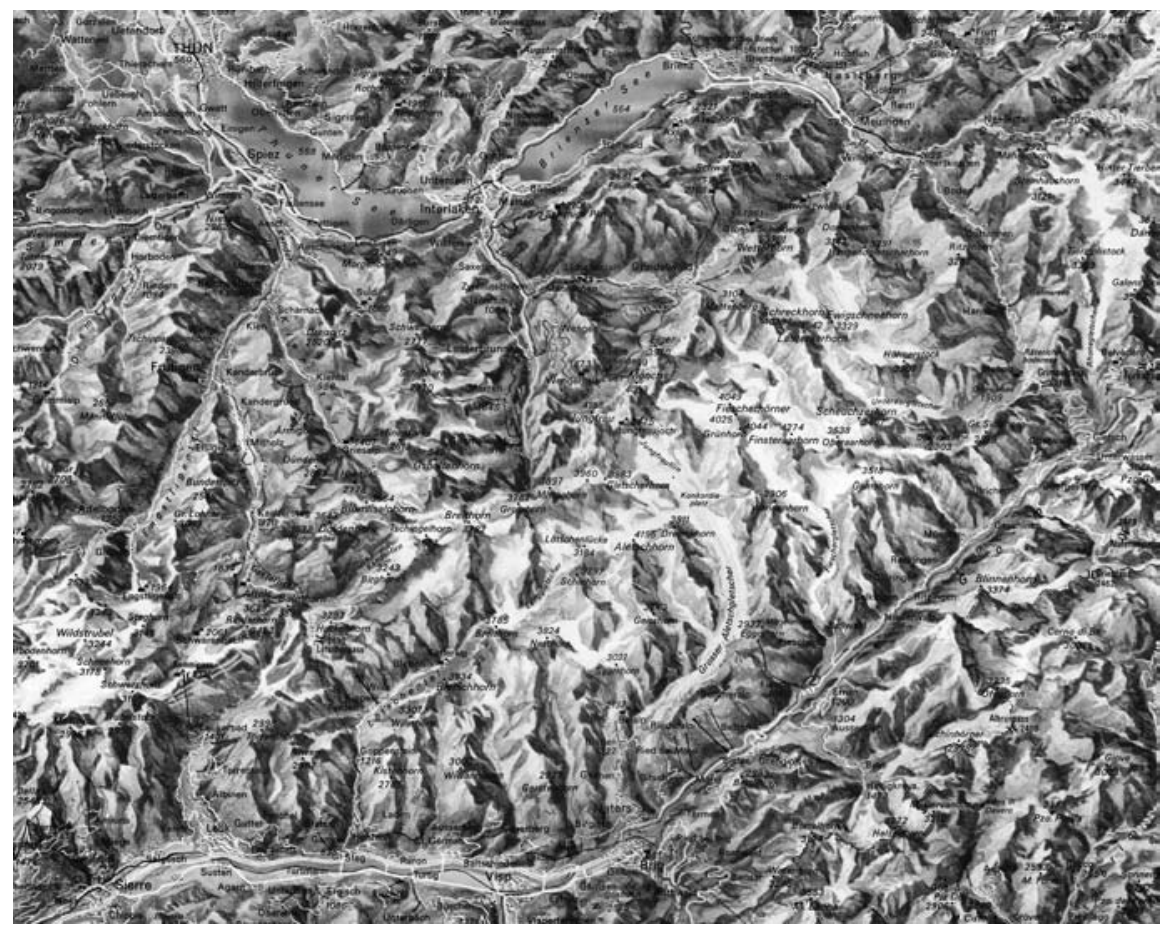

Figure 4. "A Bird's Eye View of Switzerland" by Bruno Kersten. (see page 89 for color version)

the Mercator or Mollweide. Instead, the concept of projecting rays is used. Roughly analogous to photography, virtual rays of light directed at a digital elevation model interact with it and create highlights, shadows, and intermediate tones. These tonal values then emit from the model in the form of projecting rays that cast a point onto a flat image plane that we see as rendered relief on the computer monitor. How the projected rays transfer from the model to the image plane depends on the type of projection.

Two families of projections exist for 3D relief rendering: the central perspective projection with projecting rays converging towards a focal point, and the parallel projection with parallel rays. Plan oblique relief uses the parallel projection. Starting from the left in Figure 5, the first two projections are members of the parallel projection family. In each, think of the image plane as a gigantic sheet of paper floating above the digital elevation model shown in profile. Arrows represent the projecting rays. For the orthographic projection, used for the creation of conventional shaded relief, the parallel projecting rays are perpendicular to the image plane (Figure 5, left). For the plan oblique projection, the parallel rays intersect the image plane at an angle less than $90^{\circ}$ (angle $\alpha$ in Figure 5, center). Note
". . . the first two projections are members of the parallel projection family. In each, think of the image plane as a gigantic sheet of paper floating above the digital elevation model shown in profile."

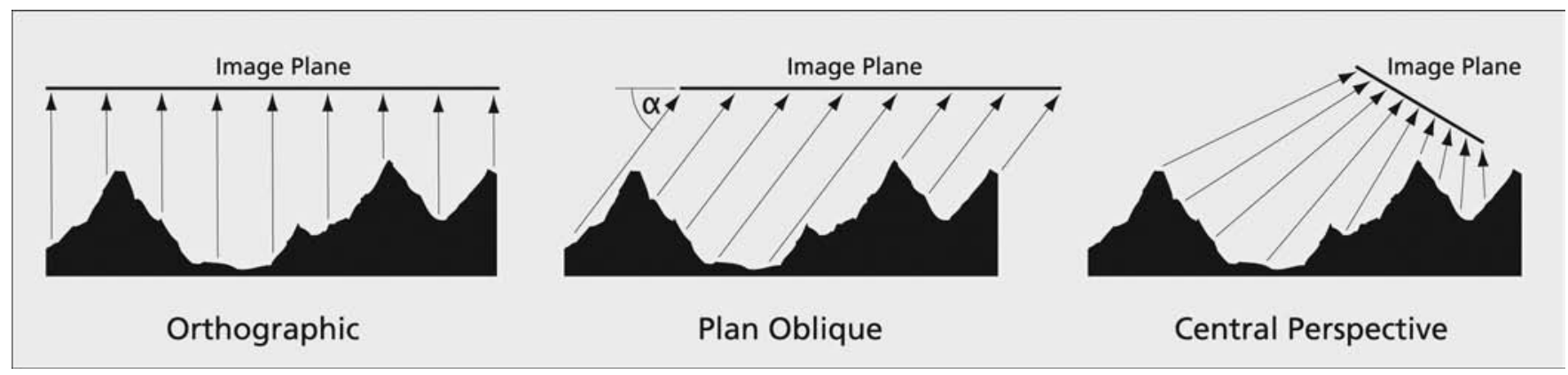

Figure 5. Projections for rendering terrain. 

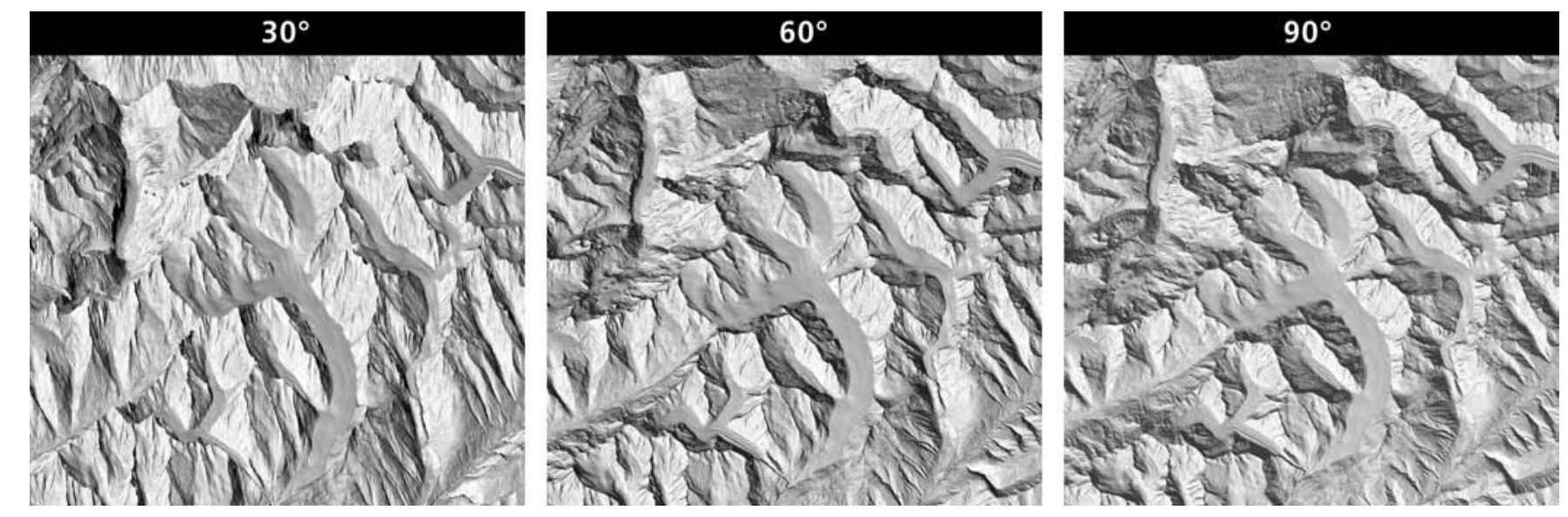

Figure 6. Plan oblique relief of the Bernese Alps, Switzerland, rendered at different inclination angles. Shallower inclination angles results in relief with greater vertical exaggeration.

that for the first two projections the image plane is oriented parallel to the planar base of the model. For plan oblique relief, this guarantees that terrain features at the same altitude render at a homogenous scale with no distortion-which would not be the case for a non-horizontal image plane or non-parallel rays. The central perspective projection, for example, has non-parallel projecting rays that converge toward a focal point behind a tilted image plane (Figure 5, right). The central perspective projection is the basis for $3 \mathrm{D}$ perspective views.

The following projection parameters control the appearance of plan oblique relief when rendered:

- The position of the image plane determines the mapped area of the final rendering.

- The rotation of the image plane around a vertical axis orients the map (for orientations other than north).

- The angle $(\alpha)$ of inclination between the image plane and the projecting rays controls vertical exaggeration of the 3D terrain. The inclination angle can theoretically vary between 0 and 90 degrees. At 90 degrees, the rendered terrain is completely orthographic and without three-dimensionality, similar to conventional shaded relief. At more acute angles, the steeper and more vertically exaggerated relief appears when rendered (Figure 6). Plan oblique relief rendered with an intermediate

inclination angle, 45 degrees, for example, results in intermediate vertical exaggeration. Note: vertically exaggerating the digital elevation model by a scale factor has the same effect as choosing a more acute inclination angle (see Appendix A for details).

- In addition to adjusting the angle of inclination parallel to viewing direction, it is also possible to tilt the projecting rays laterally (Figure 7). This action emphasizes slopes perpendicular to the viewing direction and is more investigational than practical. For most maps, altering the lateral tilt parameter from its default value of 0 degrees is not appropriate.

Appendix B explains how the angle of inclination determines the orientation of the projecting rays, and how the projecting rays transform the three-dimensional terrain model to a two-dimensional image. 

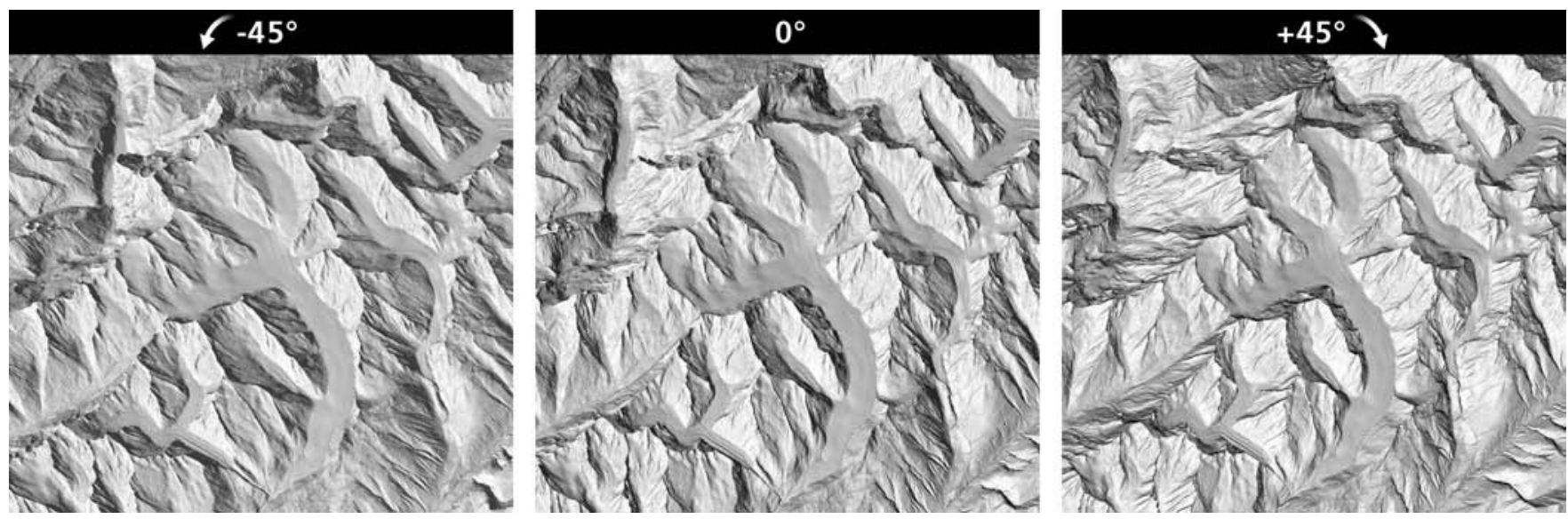

Figure 7. Plan oblique relief rendered with lateral tilt (left and right) and without (middle). Note that $-45^{\circ}$ $+45^{\circ}$ tilt reveals slopes facing to the left.

\section{Natural Scene Designer 5.0}

The creation of plan oblique relief no longer depends on prototype software or workaround techniques. Natural Graphics, the developer of Natural Scene Designer software, has added plan oblique relief as a rendering option in version 5.0 due for release in autumn 2007. Until now, creating plan oblique relief with digital data and commercial software has been difficult. A technique based on Bryce and Photoshop proved cumbersome to use, yielded maps with spatial distortion, and resulted in poor render quality (Patterson, 2004). By comparison, Natural Scene Designer 5.0 generates distortion-free terrain at a uniform resolution and with high render quality. Natural Scene Designer uses the same projection and rendering methods as our prototype software described above. Plan oblique relief created with the two software applications align exactly when overlaid on top of one another.

Creating plan oblique relief with Natural Scene Designer 5.0 is simple. It involves (1) opening a DEM; (2) selecting the "Render Planimetric Oblique Relief" from the Render drop menu; and, (3) clicking the render button. In most cases the default settings produce excellent plan oblique relief. For those seeking more options, the software permits users to set the vertical exaggeration, vary the illumination azimuth and angle, drape images, apply hypsometric tints, and control other functions that one generally expects from a mature terrain application.

\section{DESIGN CONSIDERATIONS}

Like other forms of relief representation, plan oblique relief is not the perfect solution for all maps. Understanding the technique-both the good and the bad elements-is essential for using it appropriately.

\section{Advantages of plan oblique relief}

- 3D terrain - Figure 8 shows the close resemblance of plan oblique relief generated digitally to one of Erwin Raisz's landform maps drawn by hand. Writing about the advantages of his mapping style, in 1931 Raisz observed, “... the map appeals immediately to the average [person]. It suggests actual country and enables [them] to see the land instead of an abstract location diagram. It works on the imagination. What this means can be

\author{
"The creation of plan oblique \\ relief no longer depends on \\ prototype software or \\ workaround techniques."
}

\author{
"Understanding the \\ technique-both the good and \\ the bad elements - is essential \\ for using it appropriately."
}


"Improving on the inked landform maps of Raisz, plan oblique relief depicts the elevation of flat-floored basins and plateaus in their proper relation to sea level." best appreciated by teachers."

Three quarters of a century later, his claim holds true for plan oblique relief.

- Geographic shape - Maps made with plan oblique relief retain the shape of familiar geographic areas. Plan oblique relief is free of the severe spatial distortion found in 3D perspective views: the mapped space is non-hierarchical, depicting objects in the foreground and the background at the same scale; parallel lines are parallel and do not converge towards the vanishing point; and, major landforms do not diminish to progressively smaller sizes on the horizon. On small-scale maps made with either plan oblique relief or conventional shaded relief, large geographic shapes appear similar. Plan oblique relief is not perfect in this regard, however. In areas with rugged terrain, large landforms in the foreground can occlude small geographic shapes in the background, a problem exacerbated by vertical exaggeration.

- Distance measurement - Plan oblique relief preserves distances and angles for terrain lying at the same elevation, allowing for distance measurements within a flat plain or between locations of equal elevation, such as those at sea level. Because small- and medium-scale maps are usually those that receive plan oblique relief, measurement inaccuracies caused by the planimetric displacement of landforms are relatively minor. This effect contrasts with $3 \mathrm{D}$ perspective views where perspective foreshortening makes such measurements impossible.

- Gauging altitude - Like other 3D maps, plan oblique relief permits readers to roughly gauge the relative height of landforms within a proximate area. Improving on the inked landform maps of Raisz, plan oblique relief depicts the elevation of flat-floored basins and plateaus in their proper relation to sea level. Political boundaries and other map linework conform to the profile of the terrain rising over mountain ranges and descending into canyons, providing additional hints about relative elevation (Figure 8). Furthermore, if hypsometric tints (or possibly contour lines) are draped on plan oblique relief, readers can easily and accurately determine the elevation of all points, even flat areas on the landscape.

- Reading by sections - Much as with conventional maps, to view a plan oblique relief map at alternating macro and micro zoom levels works
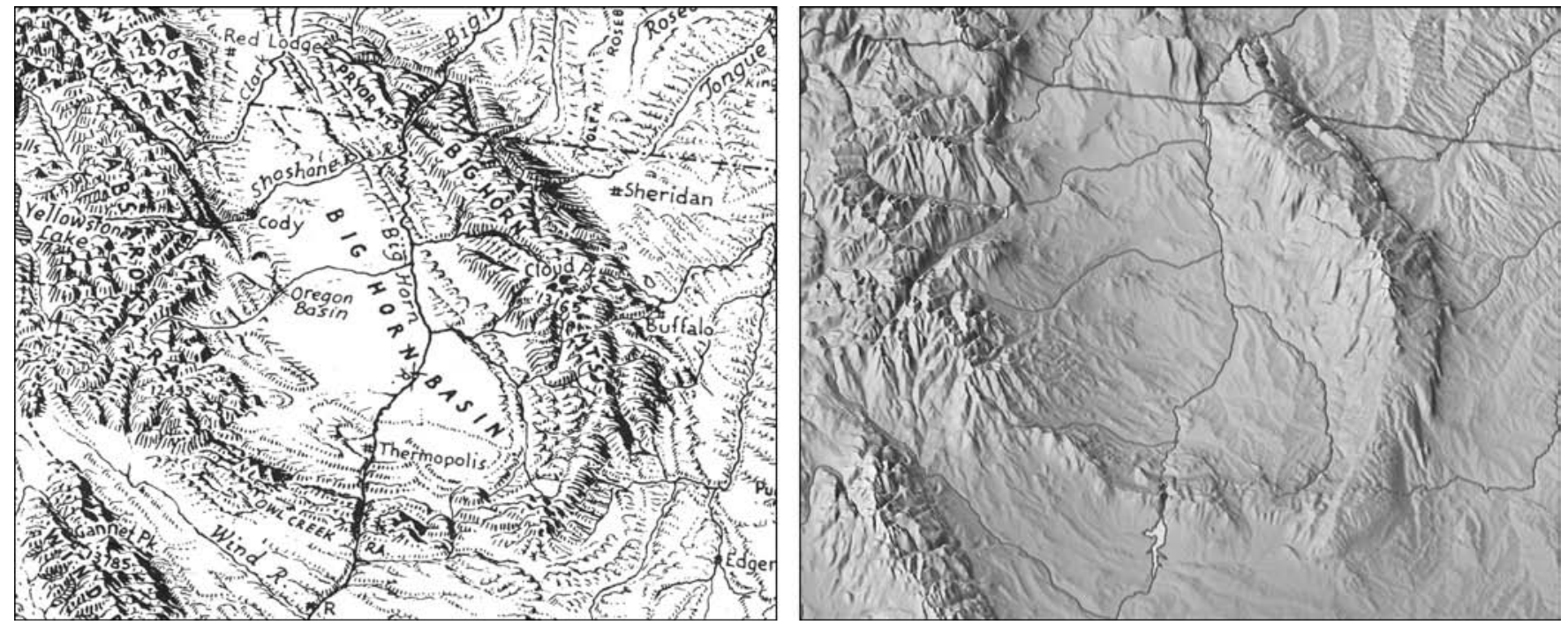

Figure 8. Bighorn Basin, Wyoming, drawn by Erwin Raisz (left) and rendered as plan oblique relief from Shuttle Radar Topography Mission data (right). Note that the state boundary on the plan oblique relief follows the profile of the terrain. On Raisz's map the terrain does not influence the boundary position. 
efficiently. Because of the uniform scale and orthographic base, reading by sections is possible- the map is both zoomable and scrollable; i.e., the observer's eye can "zoom-in" on a section of the map to read details and then scroll the image-left and right, up and down-without conflicting with the pictorial space. If one were to hide one half of a plan oblique map from view, the underlying projection would remain intact and the map would still make sense to readers (Krikke, 2000). By contrast, on 3D perspective views based on the central perspective projection, reading by sections is difficult. The reasons for this include terrain geometry that splays outward at the sides, the presence of severe terrain occlusion, and scale that diminishes with distance from the viewer.

- Wide focus - Maps with plan oblique relief project a sense of calm. While a 3D view based on the central perspective projection is ideal to convey a dynamic notion of "going there," plan oblique relief based maps are ideal for conveying the contemplative notion of "being there" (Krikke, 2000). A typical perspective view directs the eye of the reader to a destination; a typical plan oblique map has wider focus and the eye looks everywhere at once.

\section{Disadvantages of plan oblique relief}

- Unfamiliar - Because plan oblique relief is relatively rare and combines traits from shaded relief and 3D perspective views, which are well known, it has the potential to confuse readers. This problem is perhaps a greater issue among mapping professionals than to the general public, which is less beholden to existing methods of relief presentation. Plan oblique relief is more prone to cause confusion on large-scale maps than on small-scale maps.

- Occluded terrain - As with all three-dimensional terrain representations, plan oblique relief suffers from partially obscured terrain-high foreground features that block low background features-due to planimetric displacement. The back slopes of steep mountains (typically north-oriented faces on north-oriented maps) appear shortened or partially invisible. However, because plan oblique maps lack perspective, these occlusion effects are more evenly distributed and less extensive than they are in 3D perspective views. Figure 9 compares the occluded area for a 3D perspective view and plan oblique relief, both created with an inclination angle of 45 degrees. Areas that are invisible in the $3 \mathrm{D}$ perspective view and in the plan oblique relief appear as black superimposed on gray shaded relief in standard orthographic projection.

As map scale decreases so does the occluded terrain as a percentage of the total area depicted. For example, a plan oblique map of Mt. Rainier at 1:25,000-scale would occlude more of the total surface area than a map of the same size at 1:250,000-scale.

- Non-rotatable - Readers expect 3D terrain, such as that found on plan oblique relief, to point straight up. Tilting the vertical axis of rendered $3 \mathrm{D}$ terrain ruins its effectiveness and looks odd-imagine the Matterhorn canted 30 degrees from vertical. This limitation also precludes reprojecting most maps made with plan oblique relief (e.g., from Platte Carrée to an azimuthal projection). The exception to the rule is between maps with cylindrical projections where the terrain axis always remains vertical.

\section{"A typical perspective view directs the eye of the reader to a destination; a typical plan oblique map has wider focus and the eye looks everywhere at once."}

"Tilting the vertical axis of rendered $3 D$ terrain ruins its effectiveness and looks odd-imagine the Matterhorn canted 30 degrees from vertical." 

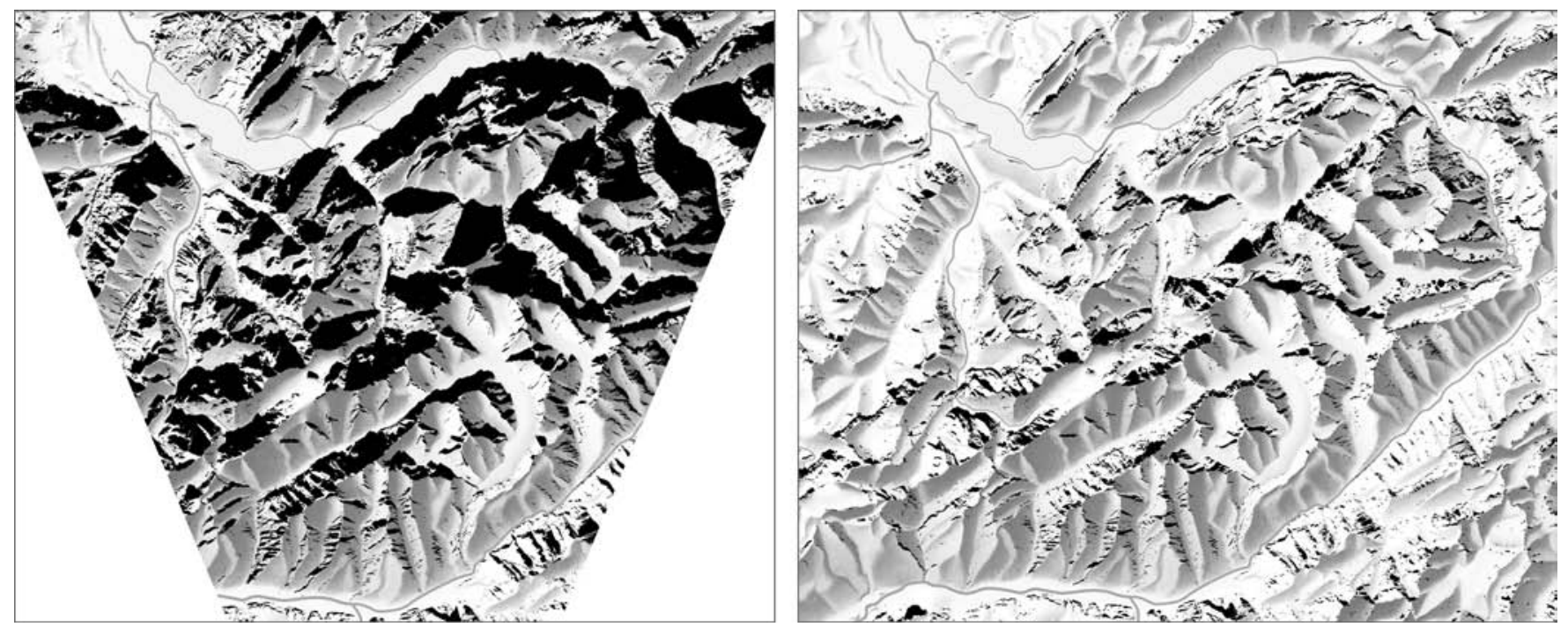

Figure 9. Occlusion maps for a 3D perspective view (left) and plan oblique relief (right) of the same geographic area; both renderings look due north and use a 45-degree inclination angle. Black represents areas of the landscape hidden from the reader and the gray shaded relief represents visible terrain. The occlusion map for the 3D perspective view appears trapezoidal due to its limited field of view.

- Linework unfriendly - The only way to fit vector linework such as drainages, boundaries, and roads on plan oblique relief is by rasterizing and then rendering it as a draped image. This process degrades the crispness of lines and requires post-rendering touchups in a paint program like Adobe Photoshop. Misregistered drainages in narrow valley bottoms are a problem because they blur and climb up hillsides in an unnatural fashion. This issue is less noticeable on conventional shaded relief maps because the drainages mask the relief below.

The following table compares the major characteristics of conventional shaded relief, plan oblique relief, and perspective 3D views.

\begin{tabular}{|c|c|c|c|c|}
\hline & 3D effect & Depiction of landforms & $\begin{array}{l}\text { Measurement of } \\
\text { distances }\end{array}$ & $\begin{array}{l}\text { Reading by } \\
\text { sections }\end{array}$ \\
\hline $\begin{array}{l}\text { Conventional } \\
\text { shaded relief }\end{array}$ & $\begin{array}{l}\text { Faux 3D } \\
\text { appearance due } \\
\text { to illumination, } \\
\text { shadows, and } \\
\text { aerial } \\
\text { perspective } \\
\text { effect. }\end{array}$ & $\begin{array}{l}\text { All major and minor } \\
\text { landforms visible throughout } \\
\text { map space, but major } \\
\text { landforms not prominent. }\end{array}$ & $\begin{array}{l}\text { Possible } \\
\text { everywhere. } \\
\text { Completely } \\
\text { planimetric. }\end{array}$ & $\begin{array}{l}\text { Possible } \\
\text { everywhere. }\end{array}$ \\
\hline $\begin{array}{l}\text { Plan oblique } \\
\text { relief } \\
\text { (Parallel } \\
\text { oblique } \\
\text { projection with } \\
\text { horizontal } \\
\text { image plane) }\end{array}$ & $\begin{array}{l}\text { 3D effect due to } \\
\text { local occlusion } \\
\text { and side-view of } \\
\text { terrain features. }\end{array}$ & $\begin{array}{l}\text { All major landforms } \\
\text { prominent. Most minor } \\
\text { landforms visible. Minor } \\
\text { occlusion and shortening of } \\
\text { back slopes, stretching of } \\
\text { front slopes. }\end{array}$ & $\begin{array}{l}\text { Possible between } \\
\text { points at equal } \\
\text { elevation. Mostly } \\
\text { planimetric. }\end{array}$ & $\begin{array}{l}\text { Possible } \\
\text { everywhere. }\end{array}$ \\
\hline $\begin{array}{l}\text { 3D view } \\
\text { (Central } \\
\text { perspective } \\
\text { projection) }\end{array}$ & $\begin{array}{l}\text { Pronounced } 3 D \\
\text { effect due to } \\
\text { occlusion and } \\
\text { perspective } \\
\text { foreshortening. }\end{array}$ & $\begin{array}{l}\text { Landforms pinch toward the } \\
\text { vanishing point in } \\
\text { background. Large areas are } \\
\text { occluded throughout map } \\
\text { space. }\end{array}$ & $\begin{array}{l}\text { Not possible. Not } \\
\text { planimetric. }\end{array}$ & $\begin{array}{l}\text { Occlusion of large } \\
\text { areas and a varying } \\
\text { scale hinders } \\
\text { reading by sections. }\end{array}$ \\
\hline
\end{tabular}




\section{Additional design considerations}

- Illumination - Light interacts with plan oblique relief just as it does with conventional shaded relief to create modulated gray tones that give form to the terrain. Using cast shadows with plan oblique is generally not advisable because they can make valley bottoms appear misregistered with drainages.

Light emanating from the lower left (southwest or west-southwest on north-oriented maps) represents the optimal direction for illuminating plan oblique relief. Illumination from the upper left, used on conventional shaded relief, does not apply-it places shadows on slopes facing the reader, which darken the map and decrease legibility. Illumination from the lower right (southeast), which is common on $3 \mathrm{D}$ perspective views, is not advisable because it tends to induce relief inversion. Xaver Imfeld and Heinrich Berann, however, successfully used lower right illumination for their maps-artistic skill and cooperative terrain helped them avoid the problem (Figure 2 and Figure 3, right). Plan oblique relief and conventional shaded relief appear very similar on maps in areas where the terrain is gentle. With this in mind, tailoring plan oblique relief to look more familiar to readers in flatter areas is possible by carefully rotating the direction of the light source from lower left toward due left. Rotating the light too much to the left, however, can result in lost detail and excessive contrast.

- Scale - Consensus exists that plan oblique relief is best suited for smallscale mapping, but at just what scale the cutoff happens is a matter for debate. According to Raisz (1953), plan oblique relief is appropriate at map scales less than 1:1,000,000. Ridd (1963) takes a broader position and advocates using it at scales possibly as large as 1:100,000. In general, however, mapmakers should exercise caution when contemplating the use of plan oblique relief at larger scales.

- Spiking - As with all 3D terrain, to apply vertical exaggeration to plan oblique relief tends to spike high solitary mountains upwards. Manipulating the DEM data with resolution bumping (Patterson, 2001) or resampling to a lower resolution before rendering can alleviate this problem.

- Vertical exaggeration - Choosing the right amount of vertical exaggeration (by varying the angle of inclination, or pitch, as it is called in Natural Scene Designer 5.0) is critical. The appropriate angle of inclination for plan oblique relief depends on the terrain's characteristics as well as on the content and purpose of the map. An angle that is too shallow generates mountains with extreme vertical exaggeration; at angles above 60 degrees, the difference from conventional shaded relief is hardly noticeable. Angles between 30 and 50 degrees generally produce the most visually pleasing plan oblique relief.

\section{PRACTICAL USES OF PLAN OBLIQUE RELIEF}

To put theory into practice the authors of this paper each created a map with plan oblique relief that imitates the style of a famous mapmaker of the past.

Bernhard Jenny's panorama of Switzerland (Figure 10, left) follows Heinrich Berann's technique of combining plan oblique relief in the foreground (the bottom 70 percent of the map) with distorted terrain and a false horizon in the background (Jenny, 2006). He used his prototype
"Xaver Imfeld and Heinrich Berann, however, successfully used lower right illumination for their maps - artistic skill and cooperative terrain helped them avoid the problem." 
software and Space Shuttle Radar Topography Mission (SRTM) elevation data to render the plan oblique relief draped with a satellite image. Patterson contributed a separate rendering of the sky and high-altitude clouds generated in Bryce 5.0, which when grafted to the top of the plan oblique relief in Adobe Photoshop, created the horizon. The sheer transformation in Photoshop brought curvature to the horizon. Seeking additional realism, Jenny added photographs of clouds, taken from an airplane, over the plan oblique relief in background areas. The end result is a faux panoramic image that combines the readability of a map in the foreground with the dynamic quality of a true panorama in the background.

Tom Patterson created the "Physical Map of the Coterminous United States," which draws its inspiration from the landform maps of Erwin Raisz (Figure 10, right). This 1:4 million-scale wall map also derives from SRTM elevation data. To produce the map Patterson used an alpha version of Natural Scene Designer 5.0. The map is comprised of multiple rendered elements that were composited in Adobe Photoshop. Besides plan oblique relief, it features cross-blended hypsometric tints that vary in color depending on how arid or humid a lowland region is-the California deserts appear brown and the Louisiana bayous are green, just as readers expect them to be. The simulated three-dimensional appearance of the map is reminiscent of the molded plastic relief maps used in school classrooms, but with subdued colors and with much greater terrain detail.
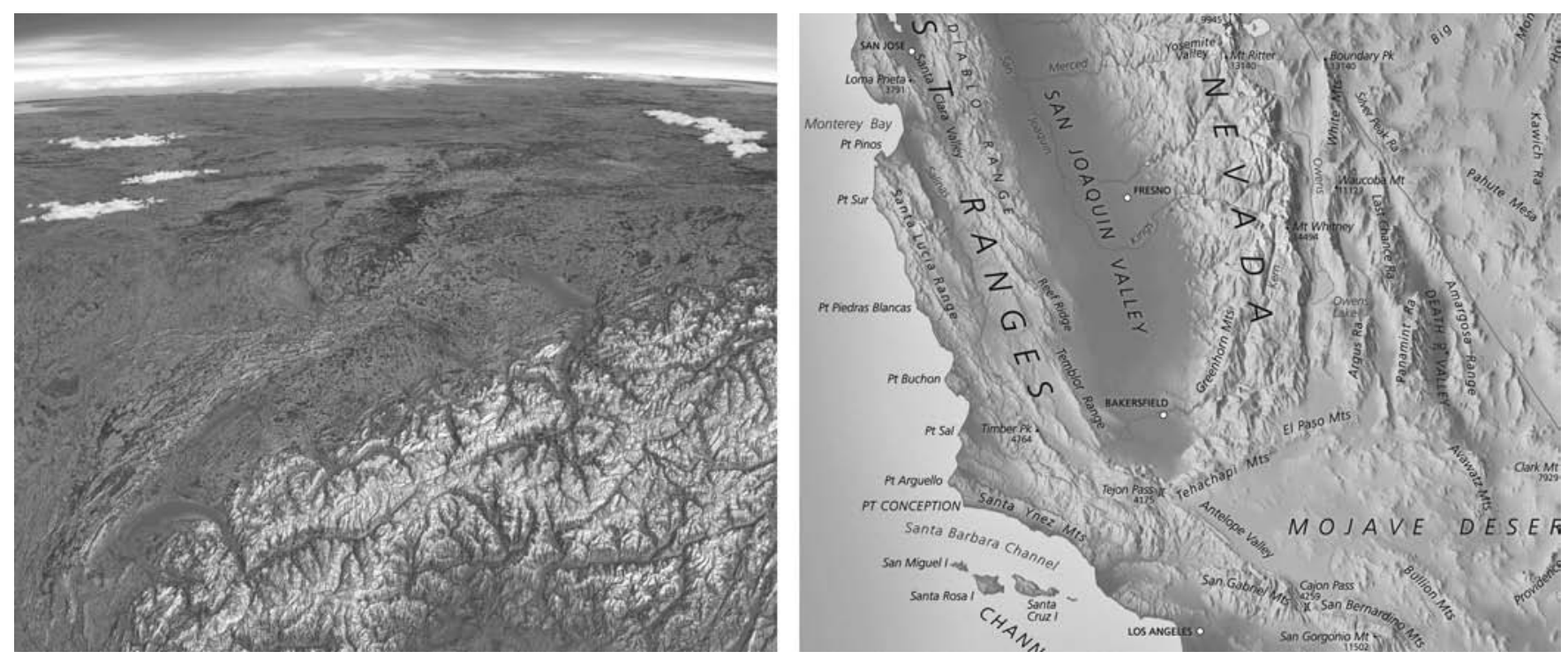

Figure 10. Panorama of Switzerland looking north (left) and an excerpt from the "Physical Map of the Coterminous United States" (right). (see page 90 for color version)

The maps discussed above are available online. For the panorama of Switzerland, go to www.reliefshading.com/planoblique. The "Physical Map of the Coterminous United States" is viewable at www.shadedrelief. $\mathrm{com} /$ physical.

Plan oblique relief is poised to shed its legacy as a manual technique used primarily by physiographers and artisans and to enter the mainstream of digital cartography. Thanks to Natural Scene Designer 5.0, a means to create it now exists at an affordable price.

The assumption throughout this paper is that for certain purposes plan oblique relief is easier for both novice and expert map readers to understand than conventional shaded relief. As Raisz pointed out: "It is a 
method that makes mountains look like mountains" (Raisz, 1948). However, whether or not plan oblique relief offers a benefit to map readers, and for what purposes, is a matter of personal opinion and anecdotal evidence. A need exists for usability studies comparing plan oblique relief to other relief presentation methods.

Having said that, the authors of this paper advise a conservative approach in using plan oblique relief. If there is any doubt about its appropriateness, use another relief presentation method. The best use of plan oblique relief is still landform mapping at small scales, especially terrain dominated by solitary peaks. As an example, when used with bathymetry data the technique yields results similar to the ocean floor maps painted by Berann (Figure 11). Having at least some dramatic terrain on a map is a prerequisite for using plan oblique relief; it makes no sense to use it when the terrain is entirely gentle. Plan oblique relief also is suited for generalized thematic mapping provided that intricate data do not overlay rugged terrain. Thematic maps that depict information broadly relating to the terrain, such as a map of South America showing the historical extent of the Inca Empire with a large area tint, lend themselves to depiction with plan oblique relief.

\author{
"It is a method that makes \\ mountains look like \\ mountains."
}

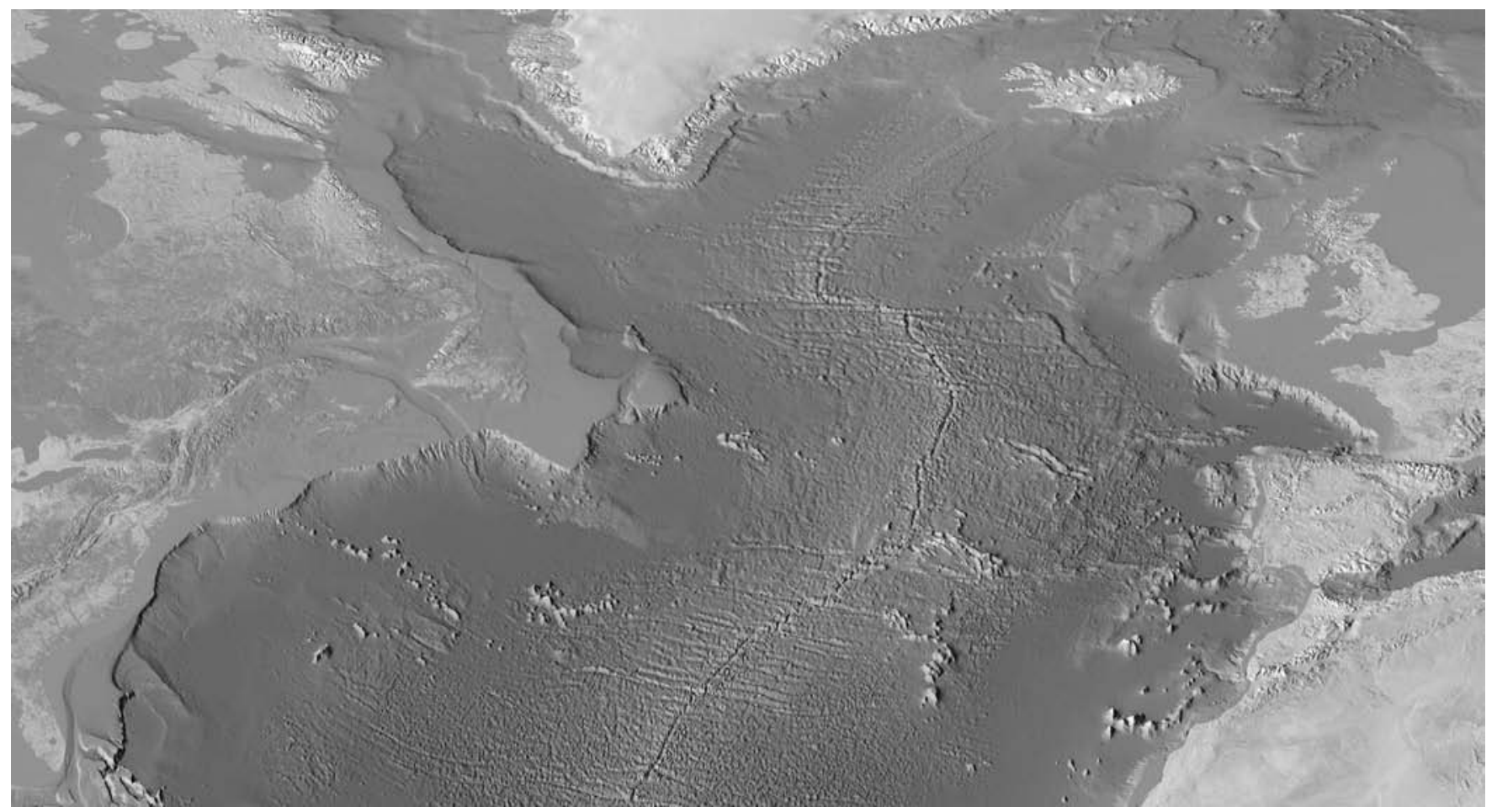

Figure 11. The North Atlantic rendered as a plan oblique relief. For a comparison with Heinrich Berann's work, see Figure 3, right. (see page 90 for color version)

There are other ways to depict plan oblique relief. For example, although plan oblique relief lacks the inked lines found on Raisz's maps, digital techniques could imitate this aspect of his work as well. Digital terrain sketching, a type of non-photorealistic rendering, is applicable to perspective views (Lesage and Visvalingam, 2002) and could be adapted to plan oblique relief. For an even closer match of Raisz's style, plan oblique relief rendered in the usual way could serve as a template for drawing pictorial landform symbols by hand (using a drawing tablet) or by cloning them in Adobe Photoshop. 
Options for enhancing digital plan oblique relief abound. Now that mapmakers can more easily make maps that emulate the masterworks of Imfeld, Raisz, and Berann, plan oblique relief will no doubt gain in popularity, and new uses for the technique await discovery.

\section{APPENDIX A - INCLINATION ANGLE AND VERTICAL EXAGGERATION RELATIONSHIP}

When rendering plan oblique relief, lowering the angle of inclination $\alpha$ (see Figure 5, middle) produces 3D terrain with greater vertical exaggeration. As one might expect, applying vertical exaggeration to a digital elevation model by a multiplication factor larger than 1 has the same effect as lowering the angle of inclination. For example, rendering a digital elevation model with an inclination angle of $26.6^{\circ}$ produces results identical to those when the digital elevation model is exaggerated vertically by a factor of 2 and then rendered with an inclination angle of 45 degrees. The equation below expresses the relationship between the angle of inclination and the vertical exaggeration.

Formula 1

$$
k=\frac{\tan \alpha}{\tan \alpha^{\prime}}
$$

With

$k$ : the factor of vertical exaggeration applied to the digital elevation model

$\alpha$ : angle of inclination for the terrain without vertical exaggeration

$\alpha^{\prime}$ : angle of inclination for the terrain with vertical exaggeration by the factor $\mathrm{k}$

\section{APPENDIX B - PLAN OBLIQUE PROJECTION ALGORITHM}

This appendix explains the details of the plan oblique projection algorithm to facilitate the inclusion of plan oblique relief in other terrain rendering software. A projection transforms three-dimensional models to a two-dimensional image - a concept that is a well-known to cartographers. Projections used in computer graphics, however, differ from cartographic projections in that they do not project lines and points specified in longitude and latitude on a sphere or ellipsoid, but work with arbitrarily shaped models defined in a three-dimensional Cartesian coordinate system.

\section{Rasterization methods}

Digital elevation models are commonly modeled as grids (elevation values arranged in regularly spaced matrices) or TINs (triangulated irregular networks). Both forms can be treated as polygon-based models; i.e., they approximate the surface of the terrain with connected triangles or rectangles. The computer graphics field has developed various techniques to project such three-dimensional objects onto a two-dimensional raster image plane. A very common rasterization technique is the so-called graphics pipeline, which is commonly used by interactive games. The graphics pipeline offers an important advantage compared to other rendering techniques: It is hardware-accelerated by modern graphics cards, which animates detailed graphical displays in real-time. The graphics pipeline usually transforms the triangle-based model to a 2D image with the cen- 
tral perspective projection - or, less frequently-with the orthogonal parallel projection. With some additional programming, the oblique parallel projection for plan oblique relief could replace these two projections (see appendix A.8 in Carlbom and Paciorek, 1978 for the projection matrix). However, we did not extend the graphics pipeline in such a way, but developed a simple ray casting algorithm, which is an alternative rasterization method that is better suited for rendering large terrain models with high graphic quality.

Ray casting, also known as ray tracing, computes each pixel in the resulting image in succession. The per-pixel computations consist of two steps. First, the algorithm determines which part of the model is shown by the pixel. For this purpose, it casts a virtual ray starting from the center of the pixel, and computes its intersection with the model. Next, the algorithm calculates a color for this intersection point; this is known as shading and texture mapping. The color is finally assigned to the pixel in the resulting image, and the algorithm repeats the same procedure for the next pixel, and so on.

\section{Ray geometry}

Before the algorithm can compute the intersection point between a ray and a digital terrain model, it has to determine the geometry of the ray. The ray is defined by the position of the pixel $P$ in the image plane floating above the terrain (Figure 5, center), and two orienting angles: the angle of inclination and the angle of lateral tilt. The direction vector $d$ of the ray can be expressed in vector geometry as:

Formula 2

$$
\vec{d}=\left[\begin{array}{c}
0 \\
\cos \alpha \\
\sin \alpha
\end{array}\right]
$$

Variable $\alpha$ is the latitude or angle of inclination rotating around the $x$-axis, counted positive from the y-axis. In the standard configuration shown in Figure 12 , $\alpha$ equals $-\pi / 4$. Note that the orthographic projection is a special case of the plan oblique projection where $\alpha$ equals $-\pi / 2$.

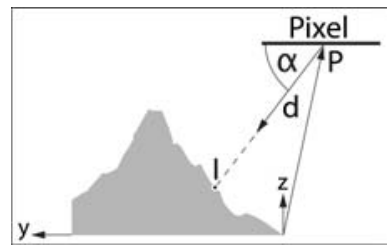

Figure 12. Ray-terrain intersection for one pixel.

Formula 2 above assumes that there is no lateral tilt. With a lateral tilt angle $\beta$, the direction vector is:

Formula 3

$$
\vec{d}=\left[\begin{array}{c}
\cos \alpha \cos \beta \\
\cos \alpha \sin \beta \\
\sin \alpha
\end{array}\right]
$$


Variable $\beta$ is the longitude rotating around the $z$-axis, counted positive from the $x$-axis. For the standard situation without a lateral tilt, $\beta$ equals $\pi / 2$. In Figure $7, \beta$ is $3 \pi / 4$ (left), $\pi / 2$ (center), and $\pi / 4$ (right).

\section{Ray-terrain intersection}

The intersection point $I$ of the ray with the terrain is (see Figure 12):

$$
\vec{I}=\vec{P}+k \vec{d}
$$

With

$I$ : the position vector of the intersection point

$P$ : the position vector of the pixel

$d$ : the unary direction vector

$k$ : a scale factor for $d$

To compute the intersection point $I$ of a ray with an object, various algorithms have been developed for planes, spheres, boxes, etc. (Watts, 2000, and Foley et al., 1997). Specialized algorithms for digital elevation models in the form of regularly spaced grids also exist (Musgrave, 1988, Qu et al, 2003).

\section{Shading and texture mapping}

After computing the intersection point between the ray and the terrain model, the algorithm calculates a color for this location. A variety of techniques exist for this purpose, which generally combine texture mapping with a shading method. Our prototype software applies standard texture mapping: the $\mathrm{x}$ and $\mathrm{y}$ coordinates of the intersection point are used to extract a color from a geo-referenced image. The prototype also computes a diffuse Lambertian reflectance for the intersection point. The color from the texture mapping and the reflectance value are finally blended and stored in the raster image.

The Lambert reflectance model is computationally simple. The gray value is proportional to the cosine of the angle between the surface normal and the light vector, which is calculated by taking the dot product of the two vectors (Foley et al., 1997). Other, more complex models could be used that aim at rendering photorealistic images (Phong, ray tracing, radiosity, etc.). Non-photorealistic methods could be worthwhile alternatives: they could produce hachuring or silhouette lines that simulate Erwin Raisz's black strokes on a white background (Lesage and Visvalingam, 2002; Whelan and Visvalingam, 2003).

ACKNOWLEDGEMENTS

SOFTWARE

MAPS
The authors wish to thank the anonymous reviewers, as well as Scott Freundschuh and John Krygier (the editors of this journal), Brett Casebolt, Ed Zahniser, Helen Jenny, Claude Vez, and Markus Oehrli for their comments and assistance.

Natural Scene Designer 5.0, Natural Graphics (www.naturalgfx.com).

Figure 2: Imfeld, X. (1887). Reliefkarte der Centralschweiz. Vertical scale 1:141,000, horizontal scale 1:100,000. Winterthur: Topographische Anstalt Wurster, Randegger \& Cie.

Figure 3 left and 8 left: Raisz, E. \& Atwood, W. (1957). Landforms of the 
United States. 1:4,525,000 (approx.), sixth revised edition. Cambridge, Massachusetts.

Figure 3 right: Heezen, B. \& Tharp, M., painted by Berann, H. (1968). Atlantic Ocean Floor. 1:30,412,800. Washington, DC: National Geographic Society.

Figure 4: Kersten, B. (1980). Die Schweiz aus der Vogelschau: A bird's eye view of Switzerland: La Suisse vue à vol d'oiseau: La Svizzera a volo d'uccello. 1:300,000. Bern: Kümmerly \& Frey.

Figure 8 right and 10 right: Patterson, T. (2006). Physical Map of the Coterminous United States. 1:4,000,000. Retrieved November 14, 2006 from http:/ / www.shadedrelief.com/physical.

Figure 10 left: Jenny, B. (2006). Biodiversität erleben - Die Naturschutzzentren und andere Erlebnisorte der Schweiz und ihrer Nachbarschaft. Approx. 1:600,000. Zürich: Schweizer Vogelschutz SVS / BirdLife Schweiz. Retrieved November 15, 2006 from http:/ / www.reliefshading.com/planoblique.

Carlbom, I. \& Paciorek, J. (1978). Planar geometric projections and viewing transformations. Computing Surveys, 10(4), 465-502.

Cavelti Hammer, M., Spichtig, K., von Flüh, N., Germann, T., Caminada, P., Feldmann H.U., \& Glatthard, T. (2006). Xaver Imfeld, 1853-1909, Meister der Alpentopografie. Sarnen, Switzerland: von Ah Druck, 191 pp.

Foley, J. D., van Dam, A., Feiner, S. K., \& Hughes, J. F. (1997). Computer graphics: Principles and practice (2nd ed.). Boston: Addison-Wesley, 1175 pp.

Imhof, E. (1982). Cartographic relief presentation (H. J. Steward, Ed.). Berlin, New York: de Gruyter, 389 pp.

Jenny, B. (2006). Design of a panorama map with plan oblique and spherical projection. Proceedings of the 5th ICA Mountain Cartography Workshop, Bohinj, Slovenia, p. 121-128 [available from http://jenny.cartography. ch/pdf/2006_Jenny_planoblique_spherical.pdf].

Hodgkiss, A. G. (1973). The bildkarten of Hermann Bollmann. The Canadian Cartographer, 10(2), 133-145.

Kennelly, P. (2002). GIS applications to historical cartographic methods to improve the understanding and visualization of contours. Journal of Geoscience Education, 50(4), 428-436.

Krikke, J. (2000). Axonometry: A matter of perspective. IEEE Computer Graphics and Applications, 20(4), 7-11.

Lawrence, D. (1999). Mountains under the sea: Marie Tharp's maps of the ocean floor shed light on the theory of continental drift. Mercator's World, $4(6), 36-43$.

Lesage P. L. \& Visvalingam, M. (2002). Towards sketch-based exploration of terrain. Computers \& Graphics, 26(2), 309-328. 
Musgrave, F. K. (1988). Grid tracing: Fast ray tracing for height fields (Technical Report YALEU/DCS/RR-639). Yale University, Dept. of Computer Science Research.

Patterson, T. (2001). DEM manipulation and 3-D terrain visualization: Techniques used by the U.S. National Park Service. Cartographica, 38(1\&2), 89-101.

Patterson, T. (2004). Creating 3D relief on 2D planimetric maps. Retrieved November 15, 2006 from http:/ / www.shadedrelief.com/planimetric/plan. html.

Qu, H., Qiu, F., Zhang, N., Kaufman, A. \& Wan, M. (2003). Ray tracing height fields. Procedings of Computer Graphics International, 2003, 202-207.

Raisz, E. (1931). The physiographic method of representing scenery on maps. Geographical Review, 21(2), 297-304.

Raisz, E. (1948). General cartography. New York [etc.]: McGraw-Hill, 354 pp.

Raisz, E. (1956). Landform maps. Petermanns geographische Mitteilungen, $100,171-172$.

Ridd, M. (1963). The proportional relief landform map. Annals of the Association of American Geographers, 53(4), 569-576.

Robinson, A. \& Thrower, N. (1957). A new method of terrain representation. Geographical Review, 47(4), 507-520.

Tanaka, K. (1932). The orthographic relief method of representing hill features on a topographic map. Geographical Journal, 79, 213-219.

Tolkien, J. R. R. Maps by Christopher Tolkien. (1994, orig. 1954). Lord of the rings: The fellowship of the ring. Boston and New York: Houghton Mifflin, 398 pp.

Watt, A. (2000). 3D computer graphics (3rd ed.). Harlow, England: AddisonWesley, $570 \mathrm{pp}$.

Whelan, J. C. \& Visvalingam, M. (2003). Formulated silhouettes for sketching terrain. Proceedings of the Theory and Practice of Computer Graphics 2003. 


\section{Color Figures}

\section{Introducing Plan Oblique Relief Bernhard Jenny and Tom Patterson}
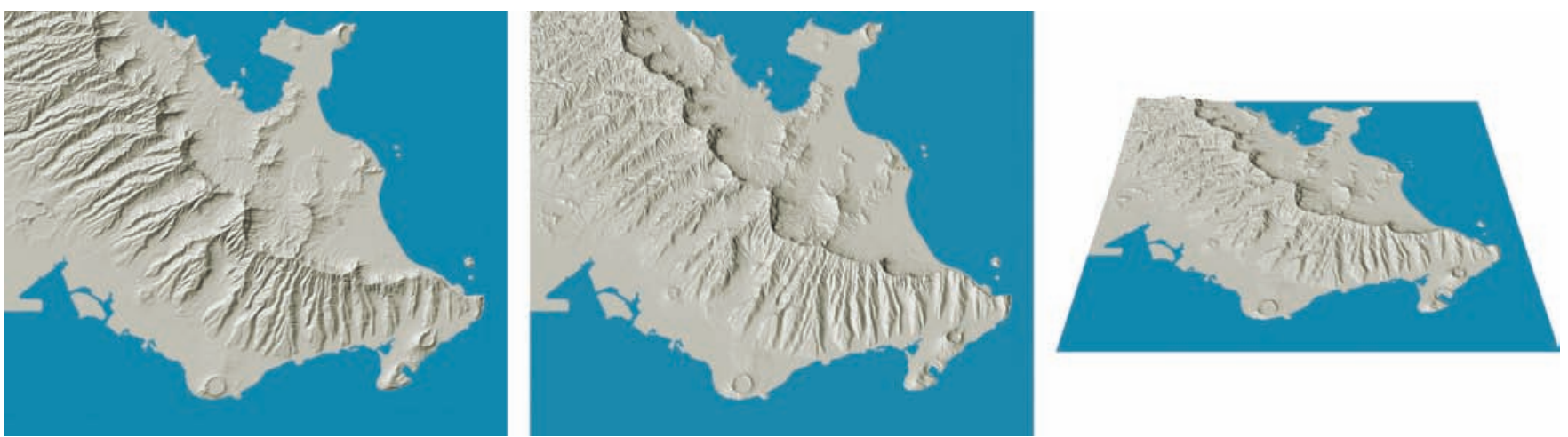

Figure 1. Southeastern Oahu, Hawaii, rendered as conventional shaded relief (left), plan oblique relief (center), and as a 3D perspective view (right)

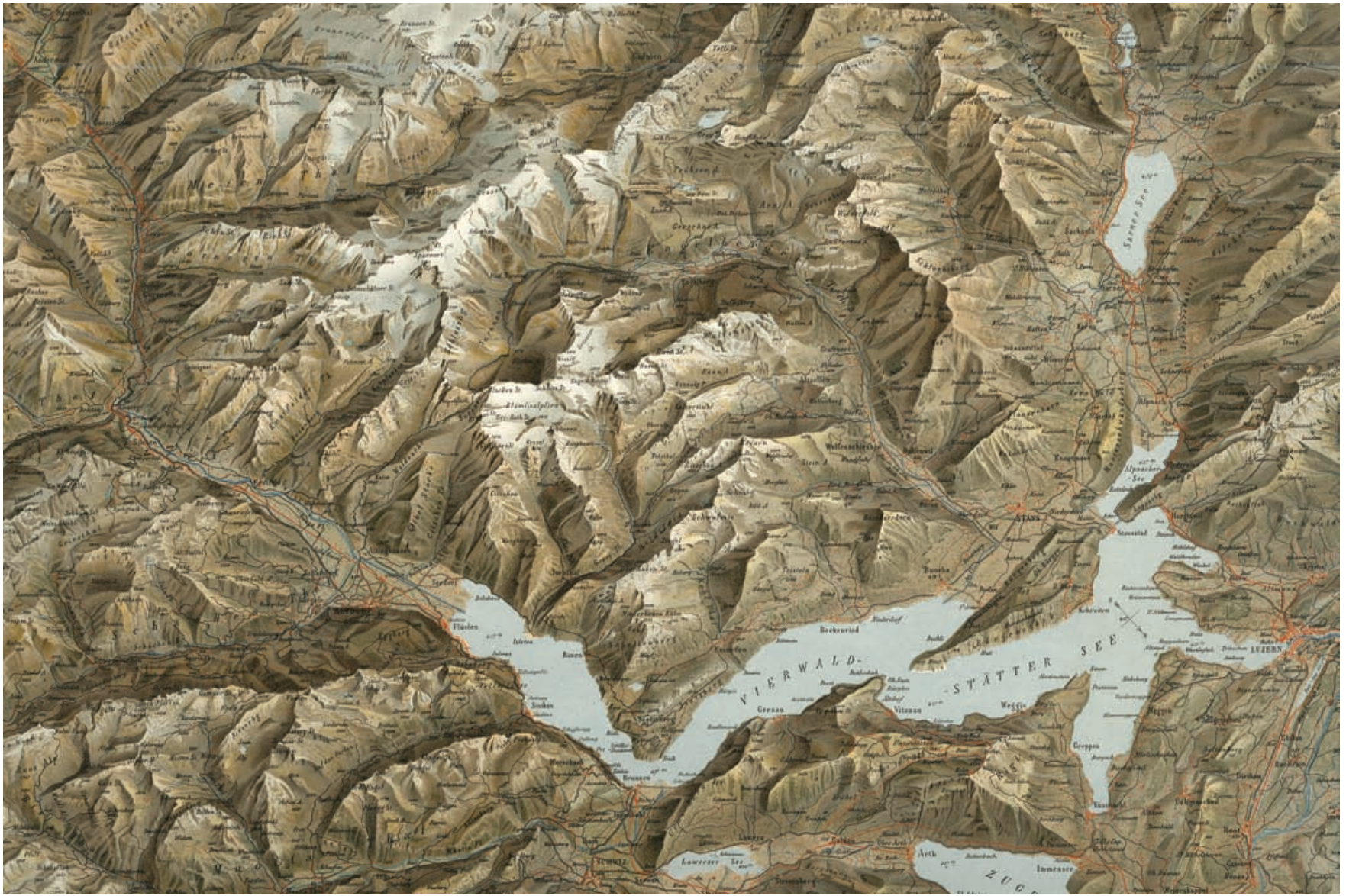

Figure 2. Xaver Imfeld's "Reliefkarte der Centralschweiz." 

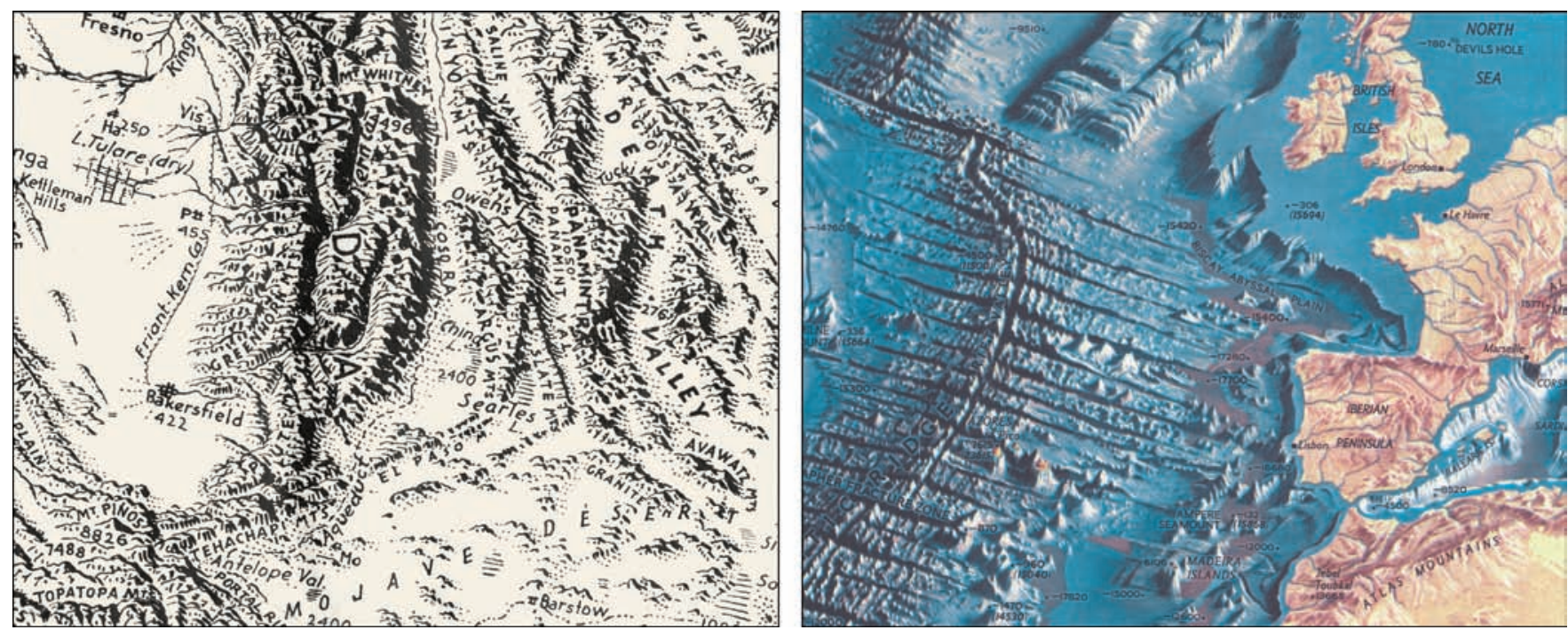

Figure 3. A sample from Erwin Raisz's 1957 "Landforms of the United States" (left) and Heinrich Berann's 1968 "Atlantic Ocean Floor," published by National Geographic Society (right). Note that Raisz uses lower left illumination and Berann lower right illumination.

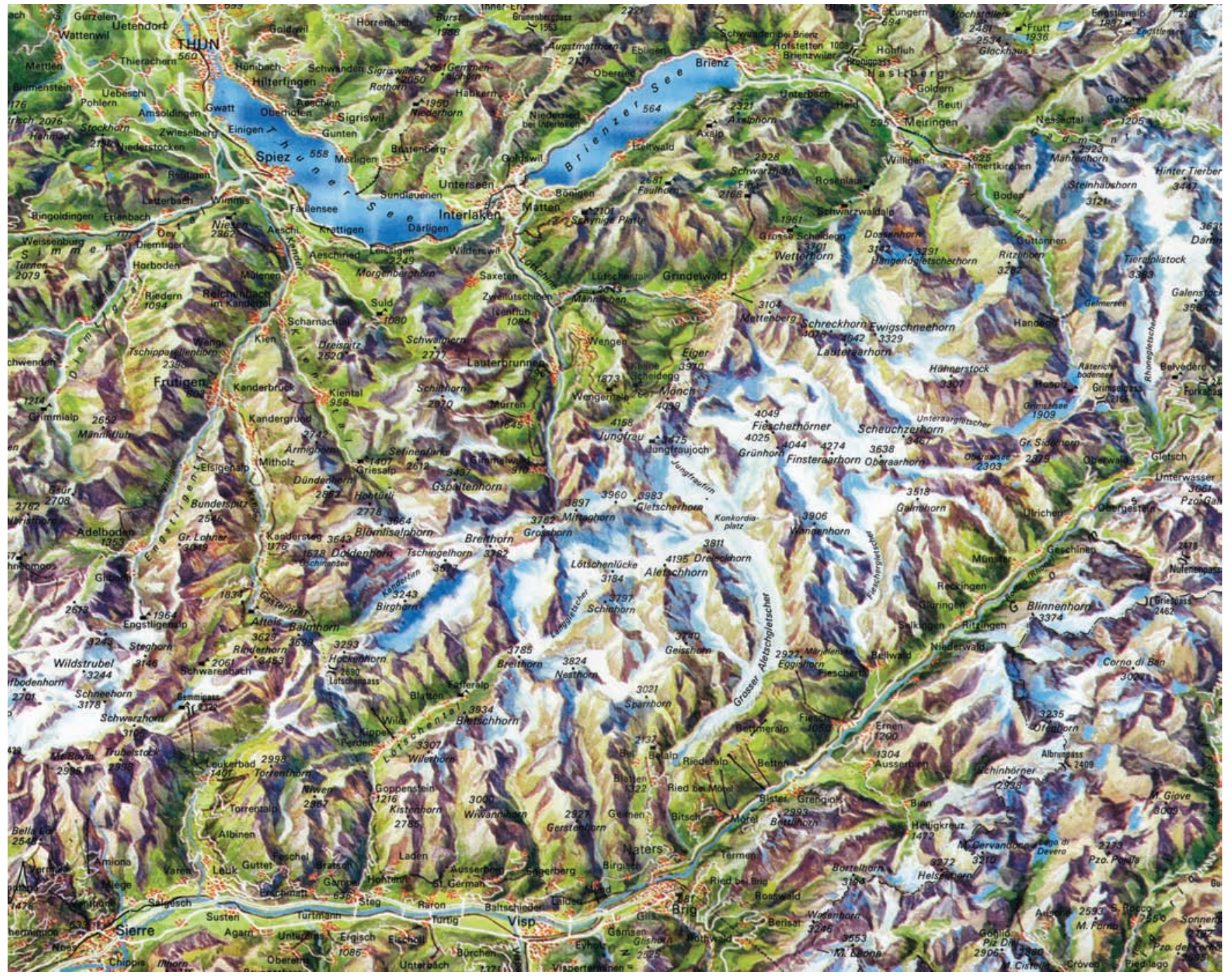

Figure 4. "A Bird's Eye View of Switzerland" by Bruno Kersten. 

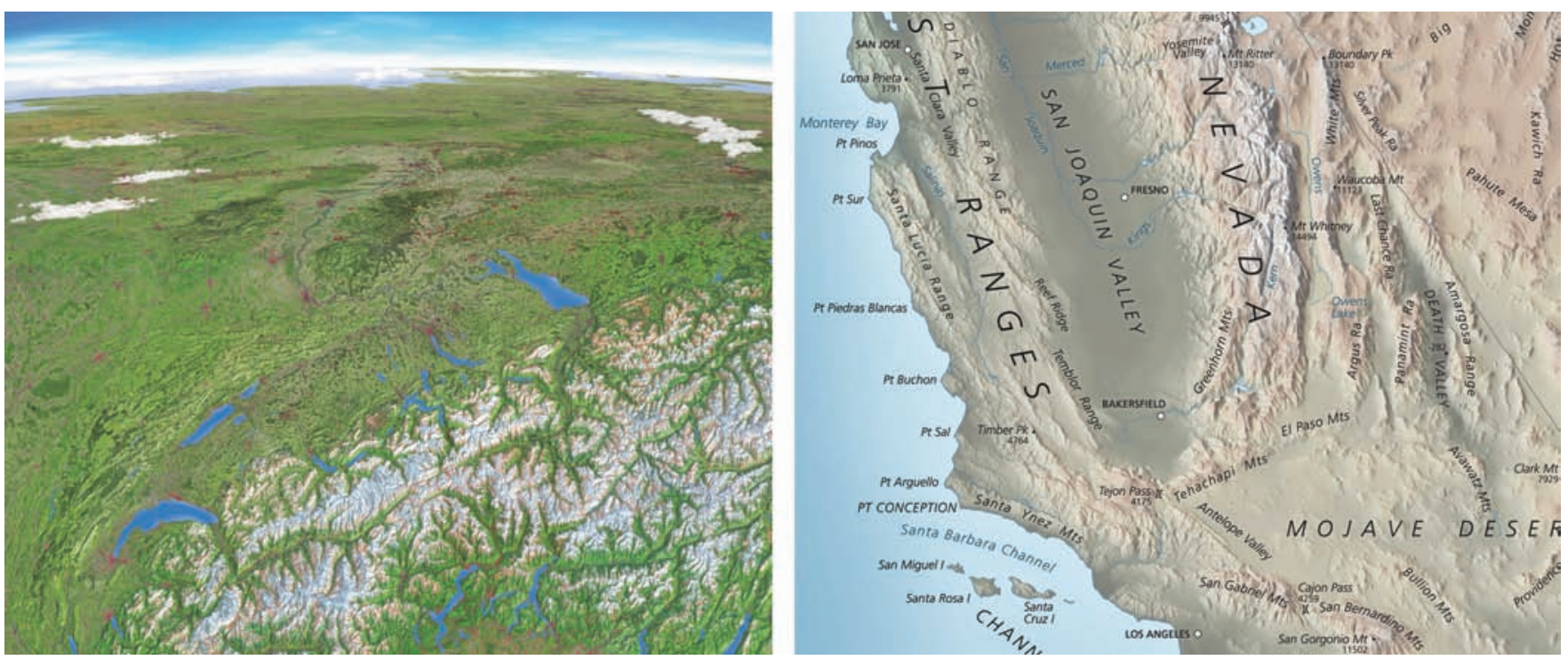

Figure 10. Panorama of Switzerland looking north (left) and an excerpt from the "Physical Map of the Coterminous United States" (right).

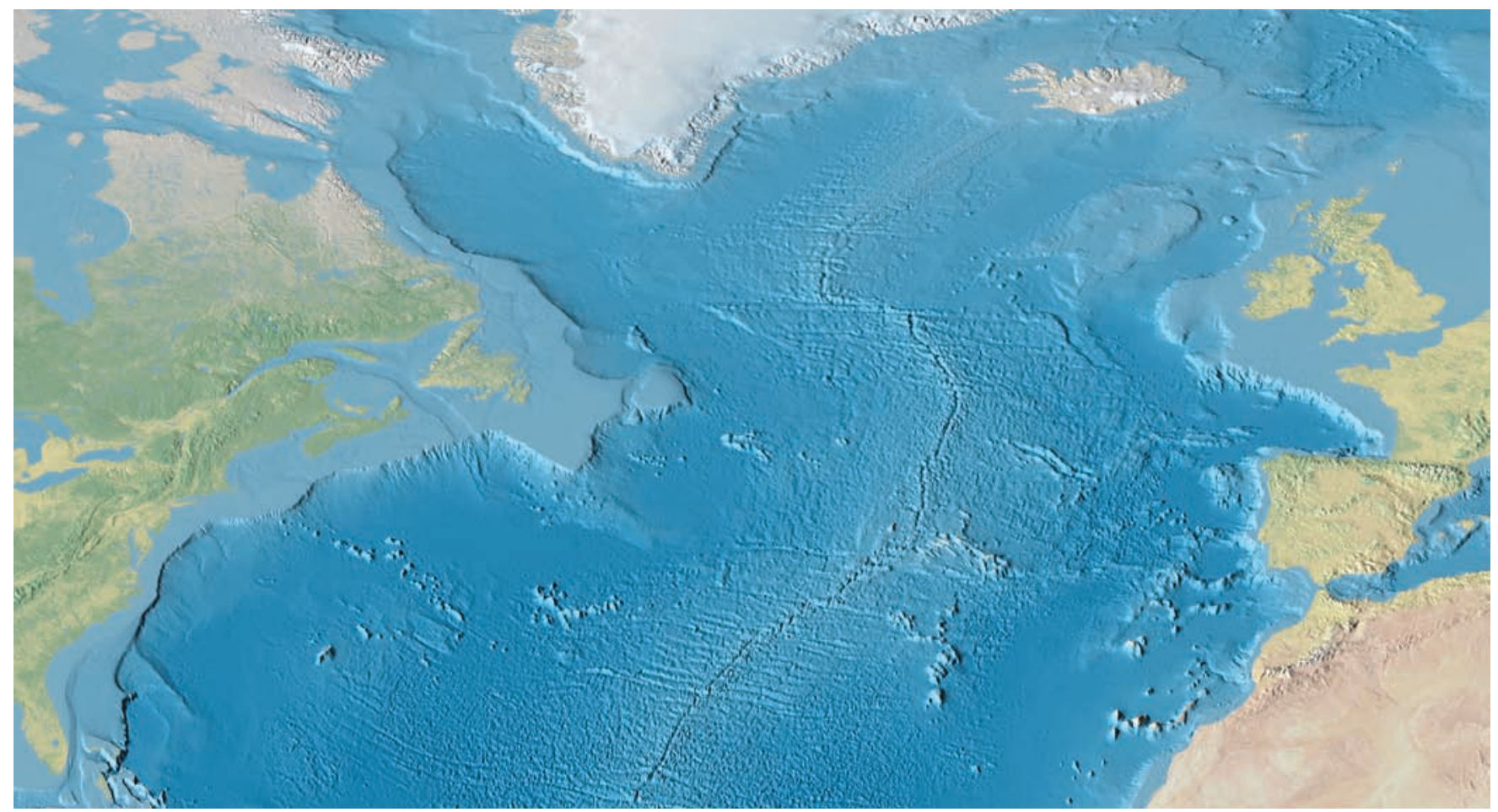

Figure 11. The North Atlantic rendered as a plan oblique relief. For a comparison with Heinrich Berann's work, see Figure 3, right. 